ORIGINAL ARTICLE

\title{
Polish version of the Cognitive Distortions Scale (CDS): Preliminary validation and personality correlates
}

\author{
Tomasz Besta ${ }^{1 \cdot A, B, C, D, E, F}$, Agata Barczak ${ }^{2 \cdot A, D, E, F}$, Aleksandra Lewandowska-Walter ${ }^{1 \cdot A, B, D, E}$, \\ David F. A. Dozois $3 \cdot D, E, F$ \\ 1: University of Gdansk, Gdansk, Poland \\ 2: Polish Association for Cognitive and Behavioural Therapy, Warsaw, Poland \\ 3: University of Western Ontario, London, Ontario, Canada
}

BACKGROUND

The aim of the two research studies presented in this article was to test the reliability and validity of the Polish version of the Cognitive Distortions Scale (CDS). The relation of the CDS to psychological measures of well-being and other theoretically relevant variables was also explored.

\section{PARTICIPANTS AND PROCEDURE}

Two correlational studies were conducted with psychology undergraduate students and their family members $(n=196$ and $n=90$, respectively). Participants completed a paperpencil set of questionnaires that contained measures of cognitive errors (study 1) and scales related to perceived quality of life and psychological well-being (study 2).
RESULTS

Preliminary results supported the reliability of the Polish version of CDS (with Cronbach's $\alpha .91$ and .90) and convergent validity as indicated by correlations with maladaptive self-views and perceived relationship quality.

\section{CONCLUSIONS}

The Polish version of CDS appears to be a reliable and valid measure of cognitive distortions.

KEY WORDS

cognitive distortions; CBT; quality of life; anxiety

CORRESPONDING AUthor - Tomasz Besta, University of Gdansk, 4 Bażyńskiego Str., 80-952 Gdansk, Poland, e-mail: t.besta@ug.edu.pl

AUthors' CONTRibution - A: Study design - B: Data collection · C: Statistical analysis · D: Data interpretation ·

E: Manuscript preparation · F: Literature search · G: Funds collection

to Cite this ARTICle - Besta, T., Barczak, A., Lewandowska-Walter, A., \& Dozois, D. J. A. (2014). Polish version of the Cognitive Distortions Scale (CDS): Preliminary validation and personality correlates. Current Issues in Personality Psychology, 2(3), 177-183. 


\section{BACKGROUND}

The focus on cognitive distortions in psychopathology has increased exponentially since the early work of Ellis and Beck many decades ago. Alford and Beck (1998) summarized one of the formal axioms of cognitive theory by stating that, "[a]lthough meanings are constructed by the person rather than being preexisting components of reality, they are correct or incorrect in relation to a given context or goal. When cognitive distortion or bias occurs meanings are dysfunctional or maladaptive (in terms of systems activation). Cognitive distortions include errors in cognitive content (meaning) cognitive processing (meaning elaboration), or both" (p. 16). This axiom certainly reflects the link of psycho(patho)logical approach to information processing and logic. Cognitive distortions can also be defined as "inaccurate or biased ways of attending to or conferring meaning upon experiences" (Barriga, Gibbs, Potter, \& Liau, 2001, p. 1). The tendency to engage in the cognitive restructuring of social information and in self-serving biases (to protect positive image of oneself or to verify one's world views and already established self-schemas) is prevalent among humans (Kwang \& Swann, Jr., 2010). Various kinds of cognitive errors are often considered important factors in development of maladaptive emotional and behavioral reactions. According to the empirical literature, the negative framing of one's experiences related to cognitive distortions can significantly impact a person's self-views, emotions and patterns of interpersonal interactions (e.g., Dozois \& Beck, 2008).

Cognitive distortions are studied in both experimental and correlational designs. A number of experimental paradigms addressing specific distortions have been developed (see Engle, Sedek, von Hecker, $\&$ McIntosh, 2005). Several measures of cognitive errors have been developed as well. For example Krantz and Hammen constructed the Cognitive Bias Questionnaire (CBQ), based on participants responses to various scenarios presented to them (Krantz \& Hammen, 1979). Other important measures of cognitive errors include the Automatic Thoughts Questionnaire (Hollon \& Kendall, 1980) and the How I Think questionnaire (Barriga et al., 2001). The abovementioned questionnaires are useful in taping some aspects of cognitive errors. However, a number of measures do not permit the examination of specific cognitive errors (Krantz \& Hammen, 1979), and some focus on measuring the exact content of thoughts, and not the cognitive distortions themselves, that lead to negative automatic thoughts (Barriga et al., 2001; Hollon $\&$ Kendall, 1980). Covin and his colleagues recently developed a measure of cognitive errors that individually assesses the frequency with which respondents experience 10 cognitive errors (Covin, Dozois,
Ogniewicz, \& Seeds, 2011). These researchers emphasized cognitive errors outlined by Burns (1980) and concentrated on those that are typically referred to in clinical practice (Covin et al., 2011). The resultant measure includes such distortions as: mind reading, catastrophizing, all-or-nothing thinking, emotional reasoning, labeling, mental filter, overgeneralization, personalization, should statements and minimizing or disqualifying the positive. The Cognitive Distortions Scale (CDS) represents a reliable measure of cognitive biases, with internal consistency (Cronbach $\alpha$ ) reported at .85 and .91. Covin et al. also demonstrated good divergent as well as concurrent validity of the scale (i.e., studies confirmed lack of a relation between CDS and social desirability, and positive correlations were obtained between CDS and scores on depression and trait anxiety).

Given that the CDS is a valid and reliable measure of cognitive distortions we decided to adapt it in to Polish. The aim of this article was to present the preliminary results on the psychometric properties of the Polish version of the CDS (Covin et al., 2011), its reliability and validity in relation to various psychological measures.

\section{STUDY 1}

The original English version of the CDS (Covin et al., 2011) was translated into Polish, and then this first version was re-translated into English by second psychologist, fluent in English. The Polish version was then corrected. This version of the scale was proofread by 20 graduate psychology students who were asked to concentrate on possible stylistics and grammatical errors. The final Polish version was than tested in two independent studies for its reliability and validity, as well as for test-retest stability.

In study 1 the relation of the CDS to already established measures of cognitive distortions and maladaptive self-schemas was explored. To evaluate the psychometric properties of the CDS, two previously established measures of cognitive biases were used. First, the How I Think questionnaire (HIT; Barriga et al., 2001), was used to establish the divergent validity of the CDS. As the HIT questionnaire is a measure of cognitive distortions related to antisocial behavior, and CDS is a tool based on peoples' metacognitive abilities, we predict that the CDS would not relate significantly to this index. To explore the concurrent validity of the CDS, we applied the Short version of the Young Schema Questionnaire (YSQ-S3; Young, Klosko, \& Weishaar, 2003), a measure of early maladaptive core beliefs that are related to the development of psychological disorders. Here we predicted, that the CDS could correlate positively with YSQ as both measures are related to generalized tendencies to distort information about oneself. As cognitive 
distortions are known to threaten the stability and well-being of couple's relationships (e.g., Beck, 1988) we also examined the link among self-described cognitive biases measured by CDS, perceived strength of the relationship with partner and family members, and the perceived quality of the relationship.

\section{PARTICIPANTS AND PROCEDURE}

\section{Participants}

In the first study, 196 people (124 female, 9 did not stated their gender; $M$ age $=26.76, S D=10.88)$ participated in paper-pencil study for course credit. To increase variation of the participants group, polish psychology undergraduates were asked to recruit another opposite sex student from a different field of study or family member. All questionnaires were presented in Polish.

\section{Measures}

Translated Cognitive Distortions Scale (Covin et al., 2011). Participants read short descriptions of the 10 cognitive distortions and answered, on Likert-type scale (ranging from 1 "never" to 7 "all the time"), how often they exhibited such behaviors in both interpersonal and achievement domains. The English version of the CDS is a reliable measure with Cronbach's $\alpha=$ $=.85$ and .91 . Reliability of the Polish version is described in details in the result section.

How I Think questionnaire (Barriga et al., 2001). This measure of cognitive distortions focuses on antisocial and aggressive behavior. The HIT contains 54, 6-point Likert items ranging from "totally agree" to "totally disagree". This scale is used to measure 4 types of cognitive distortions: self-centered (egocentric bias); blaming others; minimizing/mislabeling, assuming the worst. Overall reliability for the scale (Cronbach's $\alpha$ ) is .92.

Short version of the Young Schema Questionnaire (YSQ-S3; Young et al., 2003; polish preliminary adaptation: Oettingen, personal communication, May 24, 2013). This measure contains 90, 6-point Likert items ranging from 1 (does not describe me at all) to 6 (describes me perfectly), and is intended to identify 18 maladaptive self-schemas (see Table 1 for details). Overall reliability for the total scale is excellent (Cronbach's $\alpha=.95$ ).

Pictorial measures of personal and social identity fusion (Swann, Jr., Gómez, Seyle, Morales, \& Huici, 2009). This index was used to assess the strength of the relationship with romantic partner and one's family members. The measurement was based on a simple wordless scale. Participants indicate which picture best represents the way they perceived their relationship with partner or family and they have to choose among five symmetrical degrees of overlap $(0 \%, 25 \%, 50 \%, 75 \%$, and $100 \%)$. Option A is designated total independence of self from the partner/family ( $0 \%$ overlap) whereas option E signifies complete overlap of the self-concept and others (100\% overlap).

Cantril's Self-Anchoring Ladder (1965). A one item measures based on the Cantril's ladder was included to ask participants about the relationship quality. Answers to a question "How do you see your relationship" could vary from 1 - the worst relationship I could imagine, to 10 - the best relationship I could imagine.

\section{Procedure}

Participants were introduced to a study that was presumably conducted to explore the relationship between different thinking styles and personality variables. After this, participants completed a set of questionnaires. There was no time limit of any kind.

\section{RESULTS}

Reliability of the CDS as measured by Cronbach's $\alpha$ was good when both achievement $(\alpha=.83)$, and relationship $(\alpha=.84)$ domains were considered. The overall reliability of the scale was excellent $(\alpha=.91)$.

The concurrent and convergent validity of the Polish version of the CDS was assessed by performing a series of correlations with relevant measures included in the study 1 (see Table 1). Scores on CDS correlate more strongly to YSQ scales than to the HIT questionnaire. Additionally we explored the relationship between the CDS and the strength of the relationship with one's partner. This relation was not statistically significant. As to the relationship quality, both interpersonal and achievement subdomain of CDS are associated negatively with perceived quality of life.

To ascertain whether a significant difference existed between cognitive errors made in interpersonal contexts versus achievement contexts, a series of $t$-tests between mean results in both domains were conducted. Overall, there was a significant difference between tendencies to experience errors in interpersonal situations $(M=3.60, S D=1.05)$ and achievement situations $(M=3.44, S D=1.02), t(194)=3.64$, $p<.001$.

\section{DISCUSSION}

These preliminary results support the reliability of the Polish version of CDS and its relation to maladaptive self-views and perceived relationship quality. Weaker correlation CDS with HIT could be attributed to the fact that the HIT questionnaire was developed to measure cognitive distortions related to antisocial behavior. The findings may indicate that CDS is use- 
Table 1

Pearson correlations between CDS scales and measures employed in Study 1

\begin{tabular}{|c|c|c|c|}
\hline & $\begin{array}{c}\text { CDS - } \\
\text { Interpersonal }\end{array}$ & $\begin{array}{c}\text { CDS - } \\
\text { Achievement }\end{array}$ & CDS - Total \\
\hline HIT Self-centered bias & $.13^{\mathrm{t}}$ & .11 & $.13^{\mathrm{t}}$ \\
\hline HIT Blaming others & $.14^{*}$ & $.14^{\mathrm{t}}$ & $.15^{*}$ \\
\hline HIT Minimizing/mislabeling & .11 & .11 & .11 \\
\hline HIT Assuming the worst & $.15^{*}$ & $.16^{*}$ & $.16^{*}$ \\
\hline YSQ Emotional Deprivation & $.31^{* * *}$ & $.33^{* * *}$ & $.34^{* * *}$ \\
\hline YSQ Abandonment & $.57^{* * *}$ & $.47^{* * *}$ & $.54^{* * *}$ \\
\hline YSQ Mistrust & $.53^{* * *}$ & $.47^{* * *}$ & $.52^{* * *}$ \\
\hline YSQ Social Isolation/Alienation & $.40^{* * *}$ & $.37^{* * *}$ & $.40^{* * *}$ \\
\hline YSQ Defectiveness/Unlovability & $.46^{* * *}$ & $.48^{* * *}$ & $.49^{* * *}$ \\
\hline YSQ Failure to Achieve & $.49^{* * *}$ & $.49^{* * *}$ & $.52^{* * *}$ \\
\hline YSQ Practical Incompetence/Dependence & $.49^{* * *}$ & $.46^{* * *}$ & $.50^{* * *}$ \\
\hline YSQ Vulnerability to Harm and Illness & $.41^{* * *}$ & $.41^{* * *}$ & $.42^{* * *}$ \\
\hline YSQ Enmeshment & $.37^{* * *}$ & $.36^{* * *}$ & $.39^{* * *}$ \\
\hline YSQ Subjugation & $.50^{* * *}$ & $.40^{* * *}$ & $.48^{* * *}$ \\
\hline YSQ Self-Sacrifice & .11 & $.13^{\mathrm{t}}$ & $.12^{\mathrm{t}}$ \\
\hline YSQ Emotional Inhibition & $.34^{* * *}$ & $.35^{* * *}$ & $.36^{* * *}$ \\
\hline YSQ Unrelenting Standards & $.22^{* *}$ & $.20^{* *}$ & $.22^{* *}$ \\
\hline YSQ Entitlement Superiority & $.17^{*}$ & $.13^{\mathrm{t}}$ & $.16^{*}$ \\
\hline YSQ Insufficient Self-Control/Self-Discipline & $.25^{* * *}$ & $.25^{* * *}$ & $.26^{* * *}$ \\
\hline YSQ Admiration/Recognition-Seeking & $.36^{* * *}$ & $.27^{* * *}$ & $.33^{* * *}$ \\
\hline YSQ Pessimism/Worry & $.52^{* * *}$ & $.52^{* * *}$ & $.54^{* * *}$ \\
\hline YSQ Self-Punitiveness & $.42^{* * *}$ & $.46^{* * *}$ & $.46^{* * *}$ \\
\hline Fusion with family & -.01 & -.01 & -.01 \\
\hline Fusion with partner & -.10 & -.05 & -.08 \\
\hline Relationship quality & $-.27^{* *}$ & $-.20^{*}$ & $-.25^{* *}$ \\
\hline
\end{tabular}

Note. ${ }^{t} p<.100,{ }^{*} p<.050,{ }^{* *} p<.010,{ }^{* * *} p<.001$. Correlation analyses between CDS and Fusion with partner and Relationship quality were conducted on the sub-sample of participants who declared that they are currently in the relationship $(n=130)$.

ful tool in individuals with metacognitive abilities - to reflect on the proper thinking style and distortions. Such abilities are not the strongest characteristics of antisocial personality disorder. In contrast the YSQ, which is a more general scale of maladaptive self-schemas by definition (see Alford \& Beck, 1998), should reflect the cognitive distortions measured by the CDS, although similarly to antisocial characteristics the weakest correlations with "Cluster B" related characteristics - e.g., the entitlement schema - would require further testing of the CDS in clinical samples. Our results indirectly confirm that CDS is a measure of the cognitive errors closely associated with general maladaptive self-constructs.

\section{STUDY 2}

In study 2 we analyzed the relation between CDS and measures of anxiety, quality of life and self-views (self-esteem and self-concept clarity). Our aim was to explore if a tendency to engage in cognitive distortions is associated with one's well-being. In previous studies (Covin et al., 2011) scores on CDS were related to depression symptoms and anxiety (study 2), and to negative affect (study 1); as such, we hypothesized that the CDS would correlate negatively with quality of life and self-esteem, and positively with anxiety level. Moreover, we wanted to explore 
links between the tendency to engage in cognitive distortions and self-concept clarity (SCC). As clarity of self-concept is related positively to well-being and describes integrated, coherent and stable self-descriptions (Campbell et al., 1996), and because the CDS is related to maladaptive self-schemas and biased self-perception, we hypothesized that the relation between CDS and SCC would be negative. Additionally some of the participants were engaged in the research in study 1 and 2 (conducted 6 months later), which allowed us to explore the test-re-test stability of the Polish version of the CDS. Based on previous research on cognitive distortions and on the original version of CDS, we expected polish version of CDS to be negatively related to psychological well-being and self-certainty and positively to trait anxiety.

\section{PARTICIPANTS AND PROCEDURE}

\section{Participants}

This study was conducted 6 months after the study 1 . In study 2, 90 Polish undergraduates (75 female, $M$ age $=22.74, S D=6.39$ ) participated for course credits (47 of the participants took part in study 1 , as well).

\section{Measures}

Translated Cognitive Distortions Scale (Covin et al., 2011). Details of this measure are reviewed in Study 1.

State Trait Anxiety Inventory - Trait Anxiety Subscale (STAI; Spielberger, Gorssuch, Lushene, Vagg, \& Jacobs, 1983; polish adaptation Sosnowski \& Wrześniewski, 1983). The trait anxiety subscale of the STAI was used in this study. This 20 -item scale asks participants to indicate how much they have had different experiences of anxiety with answers varying from 1 (almost never) to 4 (almost always). Cronbach's $\alpha$ was excellent (.90) in current study.

Satisfaction With Life Scale (Pavot \& Diener, 1993; polish adaptation Juczyński, 2001). This 5-item measure was developed to assess satisfaction with the respondent's life as a whole. Responses were scored on a Likert-type scale from 1 (totally disagree) to 7 (totally agree). The scale's reliability was good $(\alpha=.87)$.

Self-concept Clarity Scale (Campbell et al., 1996). This scale is a 12-item self-report measure (e.g., "In general, I have a clear sense of who I am and what I am"; "Sometimes I feel that I am not really the person that I appear to be" and "My beliefs about myself often conflict with one another") that is a reliable and valid instrument. Responses range on a Likert-type scale from 1 (totally disagree) to 7 (totally agree). The scale's reliability was good $(\alpha=.85)$.

Rosenberg Self-esteem Scale (Rosenberg, 1965; polish adaptation Łaguna, Lachowicz-Tabaczek, \& Dzwon- kowska, 2007). This 10 -item scale is highly reliable and often used to measure global self-esteem. Participants answer if they agree to the presented questions on a Likert-type scale ranging from 1 - definitely not agree, to 4 - definitely agree. The scale's reliability in presented study was excellent, with $\alpha=.92$.

\section{Procedure}

As in study 1, participants were introduced to a study that presumably was conducted to explore the relationship between different thinking styles and personality variables. After this, participants completed the set of questionnaires.

\section{RESULTS}

Cronbach's $\alpha$ of the CDS in study 2 was again very good when both achievement $(\alpha=.82)$ and relationship $(\alpha=.81)$ domains were considered. The overall reliability of the scale was excellent $(\alpha=.90)$.

In study 2 concurrent validity of the Polish version of the CDS was assessed by performing a series of correlations with measures of self-esteem, quality of life, self-concept clarity and anxiety. As hypothesized, all measures of psychological well-being correlated negatively with the CDS and the measure of trait anxiety was positively associated with the CDS (see Table 2).

Additionally we conducted correlation analyses with one-tailed Pearson $r$ on a sample of 47 participants who were engaged in both study 1 and 2 . The correlation between mean results on CDS in study 1 and $2(r(46)=.43, p<.001)$ as well as correlations between results on interpersonal $(r(46)=.49$, $p<.001)$ and achievement sub-scales $(r(46)=.31$, $p<.050)$ demonstrated that the CDS is relatively stable across time, with the interpersonal domain showing a stronger correlation (although difference between correlations in achievement and interpersonal domain, due to small sample, was not significant; $Z=1.01, p=.310)$.

\section{DISCUSSION}

Results of study 2 provided additional support for the reliability and validity of the Polish version of CDS. The CDS correlated negatively with psychological well-being and positively with trait anxiety. Moreover, these findings resemble and complement the results of the original study, where CDS was also related to trait anxiety, depression scales and tendency to negative affect (Covin et al., 2011). Importantly, the CDS and its subscales also correlated with scores on self-concept clarity scale. This finding suggests that the tendency to exhibit cognitive distortions is not 
Polish version of the Cognitive Distortions Scale (CDS): Preliminary validation and personality correlates

Table 2

Pearson correlations between CDS scales and measures employed in Study 2

\begin{tabular}{cccc}
\hline & CDS - Interpersonal & CDS - Achievement & CDS - Total \\
\hline Anxiety & $.64^{* * *}$ & $.61^{* * *}$ & $.66^{* * *}$ \\
Quality of life & $-.40^{* * *}$ & $-.34^{* * *}$ & $-.39^{* * *}$ \\
Self-concept clarity & $-.45^{* * *}$ & $-.49^{* * *}$ & $-.50^{* * *}$ \\
Self-esteem & $-.48^{* * *}$ & $-.41^{* * *}$ & $-.47^{* * *}$ \\
\hline Note. $^{* *} p<.050,{ }^{* *} p<.010,{ }^{* * *} p<.001$. & &
\end{tabular}

only linked to lower self-esteem and lower perceived quality of life, but is also associated with less clear and less certain self-view.

\section{GENERAL DISCUSSION}

The aim of this article was to explore, in two studies, the reliability and validity of the Polish version of CDS, a measure of cognitive errors people experience in the interpersonal and achievement domains. The CDS is the only questionnaire to date that measures the full range of cognitive errors typically discussed in Cognitive-Behavioral Therapy. The Polish version of the scale appears to be a reliable and valid measure comprised of two inter-correlated sub-scales. Significant correlations between CDS scales and YSQ scales suggest that the frequency of experiencing cognitive errors is linked to maladaptive self-construals that could be responsible for interpersonal challenges. It is interesting that scores on CDS correlate more strongly with the YSQ scales which are more general measures of maladaptive self-schema, than to the HIT questionnaire which is a measure related more to antisocial and aggressive behavior. This finding suggests that the CDS taps a more general tendency to distort out-side reality based on relatively stable self-constructs. In addition, the stronger the cognitive distortions, the more maladaptive are the self-schemas. This notion is supported by a direct negative relation between scores on CDS and perceived quality of relationship - those people who more often have cognitive distortions judge their relationships as less rewarding.

Negative correlations obtained with measures of perceived quality of life, self-esteem and the CDS, indicate that the frequency of cognitive errors displayed by an individual is related to lower level of self-reported well-being. Other longitudinal studies in the future might examine the relationships between CDS and stability of self-esteem. This may be particularly interesting to explore, as longitudinal research on this link could shed light on whether the cognitive distortions people experience are associated with negative or/and unstable self-views.

To summarize the preliminary results reported in the paper, the psychometric qualities of the Polish version of the CDS questionnaire are suitable for assessing the self-assessed tendency to expressed cognitive distortions.

\section{ACKNOWLEDGMENT}

We would like to thank Dr. Agnieszka Popiel for her insightful comments on the first draft of this paper. The Polish version of the questionnaire is available by request from the first author.

\section{REFERENCES}

Alford, B., \& Beck, A. T. (1998). The integrative power of cognitive therapy. New York: Guilford Press.

Barriga, A. Q., Gibbs, J. C., Potter, G., \& Liau, A. K. (2001). How I Think (HIT) questionnaire manual. Champaign, IL: Research Press.

Beck, A. T. (1988). Love is never enough: How couples can overcome misunderstandings, resolve conflicts, and solve relationship problems through cognitive therapy. New York: Harper \& Row.

Burns, D. D. (1980). Feeling good: The new mood therapy. New York: Signet.

Campbell, J. D., Trapnell, P. D., Heine, S. J., Katz, I. M., Lavallee, L. F., \& Lehman, D. R. (1996). Self-concept clarity: measurement, personality correlates, and cultural boundaries. Journal of Personality and Social Psychology, 70, 141-156. DOI: 10.1037/00223514.70.1.141

Cantril, H. (1965). The pattern of human concerns. New Brunswick, NJ: Rutgers University Press.

Covin, R., Dozois, D. J. A., Ogniewicz, A., \& Seeds, P. M. (2011). Measuring cognitive errors: Initial development of the cognitive distortions scale (CDS). International Journal of Cognitive Therapy, 4, 297-322.

Dozois, D. J. A., \& Beck, A. T. (2008). Cognitive schemas, beliefs and assumptions. In: K. S. Dobson, \& D. J. A. Dozois (eds.), Risk factors in depression (pp. 121-143). Oxford, England: Elsevier/Academic Press.

Engle, R. W., Sedek, G., von Hecker, U., \& McIntosh, D. N. (eds.). (2005). Cognitive limitations in aging and psychopathology. New York: Cambridge University Press. 
Hollon, S. D., \& Kendall, P. C. (1980). Cognitive selfstatements in depression: development of an automatic thoughts questionnaire. Cognitive Therapy and Research, 4, 383-395.

Juczyński, Z. (2001). Narzędzia pomiaru w promocji i psychologii zdrowia [Measures in promotion and health psychology]. Warszawa: Pracownia Testów Psychologicznych Polskiego Towarzystwa Psychologicznego.

Krantz, S. E., \& Hammen, C. L. (1979). Assessment of cognitive bias in depression. Journal of Abnormal Psychology, 88, 611-619.

Kwang, T., \& Swann, W. B., Jr. (2010). Do people embrace praise even when they feel unworthy? A review of critical tests of self- enhancement versus self-verification. Personality and Social Psychology Review, 14, 263-280.

Łaguna, M., Lachowicz-Tabaczek, K., \& Dzwonkowska, I. (2007). Skala samooceny SES Morrisa Rosenberga - polska adaptacja metody [The Rosenberg Self-Esteem Scale: Polish adaptation of the scale]. Psychologia Spoteczna, 2, 164-176.

Pavot, W., \& Diener, E. (1993). Review of the Satisfaction with Life Scale. Psychological Assessment, 5, 164-172. DOI:10.1037/1040-3590.5.2.164

Rosenberg, M. (1965). Society and the adolescent self-image. Princeton, NJ: Princeton University Press.

Sosnowski, T., \& Wrześniewski, K. (1983). Polska adaptacja inwentarza STAI do badania stanu i cechy lęku [Polish adaptation of STAI inventory for measuring trait and state anxiety]. Przegląd Psychologiczny, 26, 393-412.

Spielberger, C. D., Gorssuch, R. L., Lushene, P. R., Vagg, P. R., \& Jacobs, G. A. (1983). Manual for the State-Trait Anxiety Inventory. Consulting Psychologists Press, Inc.

Swann, W. B., Jr., Gómez, A., Seyle, D. C., Morales, J. F., \& Huici, C. (2009). Identity fusion: The interplay of personal and social identities in extreme group behavior. Journal of Personality and Social Psychology, 96, 995-1011. DOI: 10.1037/a0013668

Young, J. E., Klosko, J. S., \& Weishaar, M. E. (2003). Schema therapy: a practitioner's guide. New York: Guilford Press. 